\title{
Carbon C 14-AC0010
}

National Cancer Institute

\section{Source}

National Cancer Institute. Carbon C14-AC0010. NCI Thesaurus. Code C140555.

A radioconjug ate composed of AC0010, an orally available, third generation, selective inhibitor of mutant forms of the epidermal growth factor receptor (EGFR), including the second-site resistance mutation T790M, that is labeled with the radioisotope carbon C 14 , with potential use in evaluating the pharmacokinetic profile of AC0010. Upon administration, the AC0010 moiety specifically and irreversibly binds to and inhibits the activity of mutant forms of EGFR. Labeling of AC0010 with the radioactive tracer carbon C 14 allows for the evaluation of AC0010's pharmacokinetic profile, including its absorption, distribution, metabolism, and excretion (ADME). 